\title{
Comportamiento de la COVID-19 en personas menores de 60 años en un hospital de tercer nivel de la Ciudad de México
}

\author{
Behavior of COVID-19 in people under 60 years of age in a tertiary hospital in Mexico \\ City
}

\author{
Alejandro Hernández-Solís ${ }^{1}$, M. Inés Quintanar-Ramírez', Andrea Quintana-Martínez', \\ Catalina Casillas-Suárez', Pablo Álvarez-Maldonado ${ }^{1}$ y Arturo Reding-Bernal** \\ ${ }^{1}$ Servicio de Neumología y Cirugía de Tórax; '2Dirección de Investigación. Hospital General de México Dr. Eduardo Liceaga, Ciudad de México, \\ México
}

Estimado editor:

En un hospital de tercer nivel de la Ciudad de México se realizó un estudio transversal, analizando 1006 pacientes confirmados con infección por SARS-CoV-2 mediante prueba de reacción en cadena de la polimerasa en tiempo real, de febrero a junio de 2020. Los menores de 60 años correspondieron al $65.5 \%$ (659), con edad media de 46.2 años, el $63.7 \%$ (419) fueron hombres, el $71.6 \%$ presentó al menos una comorbilidad y el $25.9 \%$ (168) requirió ingreso en la unidad de cuidados intensivos respiratorios (Tabla 1). Al realizar un modelo de regresión logística múltiple se encontró que los menores de 60 años tuvieron una razón de momios (RM) de 0.36 ( $p<0.001)$, es decir, un $64 \%$ menor posibilidad de morir por COVID-19, en comparación con los mayores de 60 años. Los hombres presentaron una RM de 1.46 ( $p=0.015)$ de morir en comparación con las mujeres, y las personas con enfermedad renal presentaron una RM de 2.02 $(p=0.007)$ de morir en comparación con las que no la tenían. La literatura indica que la diabetes, la hipertensión y las enfermedades cardiovasculares y respiratorias se asocian con mayor mortalidad, pero en nuestro estudio ninguna de estas variables resultó ser significativa ${ }^{1}$. El $28.4 \%$ de nuestros pacientes no contaba con comorbilidad; una posible explicación es la susceptibilidad y la variabilidad genética en los genes del complejo principal de histocompatibilidad de clase I (antígeno leucocitario humano $A, B$ y C) y la gravedad de la infección por el SARS-CoV- $2^{2}$. En México, el grupo de menores de 60 años corresponde al $52.07 \%$ de los infectados, y generalmente el inicio es con manifestaciones atípicas y más leve que en los pacientes mayores. En nuestro estudio, la gravedad clínica al ingreso hospitalario fue moderada en el $48.6 \%$. Las personas en alto riesgo deben tener medidas de previsión, ya que si contraen la enfermedad probablemente necesiten atención hospitalaria. En nuestra serie, el $13.3 \%$ no tomó medidas de distanciamiento social y fallecieron el $20.3 \%$ de los pacientes, incrementando los años de vida potencialmente perdidos atribuibles a muertes prematuras $^{3,4}$.

\footnotetext{
Correspondencia:

*Arturo Reding-Bernal

Dr. Balmis, 148

Col. Doctores, Cuauhtémoc

Fecha de recepción: 10-09-2021

Cir Cir. 2022;90(1):137-139

C.P. 06726, Ciudad de México, México

Fecha de aceptación: 15-09-2021

Contents available at PubMed

E-mail: reding_79@yahoo.com

DOI: 10.24875/CIRU.21000709

www.cirugiaycirujanos.com

0009-7411/@ 2021 Academia Mexicana de Cirugía. Publicado por Permanyer. Este es un artículo open access bajo la licencia CC BY-NC-ND (http://creativecommons.org/licenses/by-nc-nd/4.0/).
} 
Tabla 1. Características sociodemográficas y clínicas de la población según grupos de edad

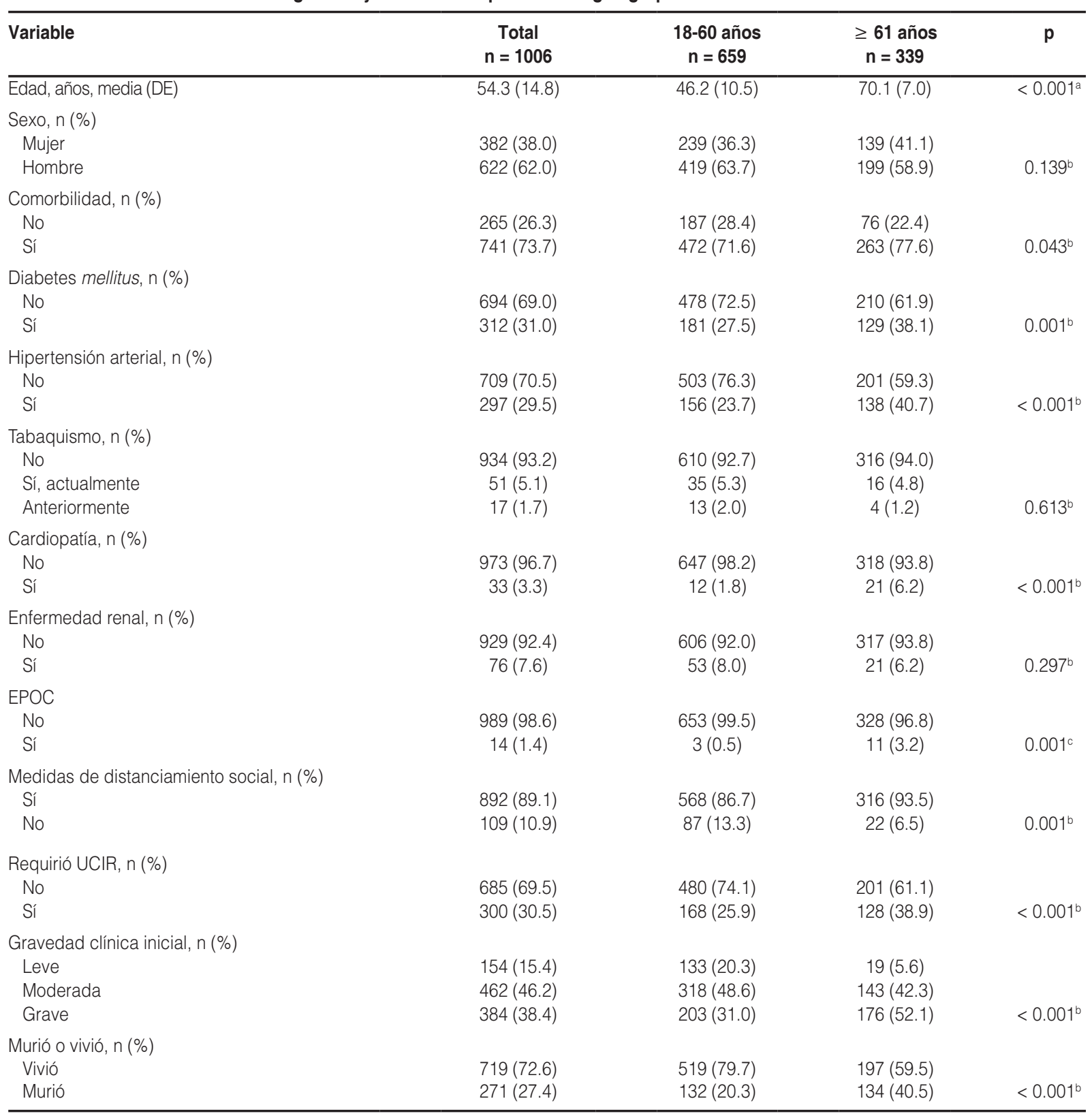

DE: desviación estándar; EPOC: enfermedad pulmonar obstructiva crónica; UCIR: unidad de cuidados intensivos respiratorios.

aPrueba U de Mann-Whitney.

'Prueba $\chi^{2}$.

cPrueba exacta de Fisher.

\section{Agradecimientos}

Los autores agradecen al personal médico y de enfermería de la torre de cardio-neumología del Hospital General de México Dr. Eduardo Liceaga.

\section{Financiamiento}

Este trabajo no recibió financiamiento alguno.

\section{Conflicto de intereses}

Los autores declaran no tener conflicto de intereses.

\section{Responsabilidades éticas}

Protección de personas y animales. Los autores declaran que para esta investigación no se han 


\section{realizado experimentos en seres humanos ni en Bibliografía}

animales.

Confidencialidad de los datos. Los autores declaran que han seguido los protocolos de su centro de trabajo sobre la publicación de datos de pacientes.

Derecho a la privacidad y consentimiento informado. Los autores declaran que en este artículo no aparecen datos de pacientes.

1. Kelvin AA, Halperin S. COVID-19 in children: the link in the transmission chain. Lancet Infect Dis. 2020:20:633-4.

2. Godri Pollitt KJ, Peccia J, Ko Al, Kaminski N, De la Cruz CS, Nebert DW, et al. COVID-19 vulnerability: the potential impact of genetic susceptibility and airborne transmission. Hum Genomics. 2020;14:17.

3. Jordan RE, Adab P, Cheng KK. Covid-19: risk factors for severe disease and death. BMJ. 2020;368:m1198.

4. Huang L, Zhang X, Zhang X, Wei Z, Zhang L, Xu J, et al. Rapid asymptomatic transmission of COVID-19 during the incubation period demonstrating strong infectivity in a cluster of youngsters aged 16-23 years outside Wuhan and characteristics of young patients with COVID-19: a prospective contact-tracing study. J Infect. 2020;80:e1-e13. 